\title{
To Determine Role of C-reactive Protein Test and Computerised Tomography Scan of Lung in Diagnosis of COVID-19
}

\author{
K. Bhagya (D), E. Subbalakshmi* (D) and V. Kalpana Devi \\ Department of Microbiology, ACS Medical College and Hospital, Dr.M.G.R. Educational and Research Institute, \\ Chennai, Tamil Nadu, India.
}

\begin{abstract}
The outbreak of novel Coronavirus Disease 2019 (COVID-19) has led the entire world to limp. The virus is causing the severe acute respiratory syndrome, with increasing morbidity and mortality. The WHO declared COVID-19 as a pandemic or public health emergency because of its morbidity and mortality. Several inflammatory markers have been used in the initial diagnosis, as well as prognostic markers in disease progression. One of the inflammatory markers is $\mathrm{C}$ reactive protein. The other markers that help in prognosis are ferritin, neutrophil-lymphocyte ratio, CT scan of the lung, IL6 (interleukin 6), RT PCR is reliable diagnostic evidence. Aim of the study: 1 . The aim is to determine the C-reactive protein, CT (Computerised Tomography) scan of the lung, RT PCR (Reverse Transcriptase Polymerase Chain reaction) in COVID-19 patients. 2. To compare CRP \& CT scan values of the lung in various age groups. A cross-sectional study was done from September 2020 to January 2021 and the results were analysed. Out of 704 covid positive patients, the maximum number of patients were in the age group between 31 to 70 . The RT PCR showed COVID positive results in 689 (97.8\%) patients. The CRP values were found to be $>25 \mathrm{mg} / \mathrm{I}$ from $31-50$ (34.7\%) years and in $\mathbf{5 1 - 7 0}$ years of age (52\%). In comparison of CT scan with CRP changes, CRP values were found to be raised when there is $25-50 \%(24.5 \%)$ and $>50 \%(27.6 \%)$ involvement of lung by COVID. CT scan lung involvement was $>50 \%$ in the age group between 31-50 (38.9\%) and 51-70 (50\%), respectively. High CRP values of $>25 \mathrm{mg} / \mathrm{I}$ were observed with the same age group $34.7 \%$ with the group of $31-50$ and $52 \%$ with the group of $51-70$, respectively. CRP correlated with the advancing age group and was found to be a good predictor of disease progression.
\end{abstract}

Keywords: $\mathrm{C}$ reactive protein, CT lung, RT PCR

*Correspondence: subhalakshmi69@gmail.com; 9845105816

(Received: March 12, 2021; accepted: June 10, 2021)

Citation: Bhagya K, Subbalakshmi E, Devi VK. To Determine Role of C-reactive Protein Test and Computerised Tomography Scan of Lung in Diagnosis of COVID-19. J Pure App/ Microbiol. 2021;15(3):1198-1203. doi: 10.22207/JPAM.15.3.09

(C) The Author(s) 2021. Open Access. This article is distributed under the terms of the Creative Commons Attribution 4.0 International License which permits unrestricted use, sharing, distribution, and reproduction in any medium, provided you give appropriate credit to the original author(s) and the source, provide a link to the Creative Commons license, and indicate if changes were made. 


\section{INTRODUCTION}

The Coronavirus Disease 2019 (COVID-19) was reported first in Wuhan, China, in December 2019. ${ }^{1}$ The severe acute respiratory syndrome coronavirus-2 (SARS-CoV-2) is an enveloped RNA virus that is grouped under SARS (Severe acute respiratory syndrome) virus. The disease started to spread so rapidly that by March 6, 2020, we figured around 80,651 cases and 3070 deaths were noted across the mainland of China. ${ }^{2}$ Outside China, SARS-CoV-2 started to spread around the world, especially in South Korea, Iran, Italy and India etc. ${ }^{3}$ In the present scenario we have come across $70,00,000$ cases reported as on February 11,2021 . Now, the mutant strain has risen and led to a lockdown in many countries. The World Health Organisation (WHO) gave a clear indication of the risk of spread and the impact of COVID-19 to be extremely high at a global level on February 28,2020 . Several preventive measures were taken across the world with a heavy campaign to reduce the spread of virus and also to decrease the mortality. This pandemic has paralysed the whole world and continues to be even now. The symptoms arising from COVID-19 infection at the initial phase generally include fever, dry cough, and malaise that are non-specific. Unlike human coronavirus infections, upper respiratory symptoms are notably infrequent. We encounter common laboratory findings on admission to hospital such as lymphopenia and bilateral ground-glass opacity or consolidation in chest CT scans besides positive RT-PCR. We should be able to assess them initially with the laboratory parameter to improve the morbidity. ${ }^{4}$ In general in the affected patient population, $>20 \%$ of the people infected with SARSCoV-2 develop life-threatening complications. The systemic inflammatory response to the SARSCoV-2 infection is a hallmark of 2019, and most hospitalized patients with COVID-19 have abnormal inflammatory biomarkers. ${ }^{5}$ Several inflammatory markers help in early pickup of severely affected patients. C-reactive protein (CRP) is an acute-phase protein synthesized by the liver whose level rises in inflammation. CRP levels are usually raised in bacterial infection mainly than in viral infection. Elevated CRP concentrations were associated with cardiovascular disease, surgical patients with severe infection, autoimmune disorders like rheumatoid arthritis, thromboembolism, and deep vein thrombosis. Elevated CRP levels have been found in viral infections like H1N1 influenza, acute respiratory syndrome like Middle East Respiratory syndrome. CT scan of the lung played an important role in assessing the severity of disease in case RT PCR is negative. ${ }^{4}$ In our study we assessed the correlation between CRP, lung lesion based on CT scan besides RT PCR to assess the severity and in management and prognosis of the disease. Objective

1. The aim of this study is to determine the C-reactive protein value, CT scan lung score, RT PCR in COVID-19 patients at a tertiary care teaching hospital.

2. To compare the CRP value and CT scan involvement of the chest in different age groups.

\section{MATERIALS AND METHODS}

The study was done at a tertiary care teaching hospital from September 2020 to January 2021. institution.

Ethical clearance was obtained from the

\section{Study population}

The population included in this study were all patients who came with symptoms suggestive of COVID-19 and above the age of 5 years.

\section{Inclusion criteria}

All patients who were tested positive for COVID-19 (either RT PCR or Based on CT chest) and also those above the age of 5 years.

\section{Exclusion criteria}

All patients who were found to be tested negative for COVID-19 were excluded from the study. Note in our results, ND denotes not detected in that particular test but would have been found to be COVID positive by other tests.

\section{Duration of the study}

From September 2020 to January 2021. Study is a cross sectional survey.

\section{Statistical Methods}

The statistical analysis was done by Descriptive and inferential statistical analysis. Results on continuous measurements were presented on Mean \pm SD (Min-Max) and results on categorical measurements were presented in Number (\%). Significance was assessed at $5 \%$ level of significance. The following assumptions 
on data were made, Assumptions: 1. Dependent variables should be normally distributed, 2 . Samples drawn from the population should be random, and Chi-square/ Fisher Exact test was used to find the significance of study parameters on categorical scale between two or more groups, Non-parametric setting for Qualitative data analysis. Fisher Exact test was used when cell samples were exceedingly small ${ }^{6-9}$.

CRP is a passive agglutination test. The test was done according to the instructions given by the kit insert. (Aspen laboratories, Himachal Pradesh, India). The results observed were qualitative which correspond to $6 \mathrm{mg} / \mathrm{dl}$. Semi-quantitative analysis was done by dilution of the serum and the results were expressed by multiplying with the dilution factor and expressed in $\mathrm{mg} / \mathrm{l}$. RT-PCR was done by extraction of the RNA virus from the sample of nasal swab and oropharyngeal swab (2 swabs), the amplification of the curve was observed, and the CT value was (threshold cut-off value) expressed as positive or negative. Note: The threshold cut-off value varies with the kit insert. (Meril Diagnostics Pvt Ltd., Andheri East, Mumbai,India) is used in our lab. This is a qualitative assay. In addition, CT scan assessed the changes in the lung and CT scores were given based on the involvement of the lung. The reporting of chest $\mathrm{CT}$ patients suspected to be having COVID-19 were categorised based on

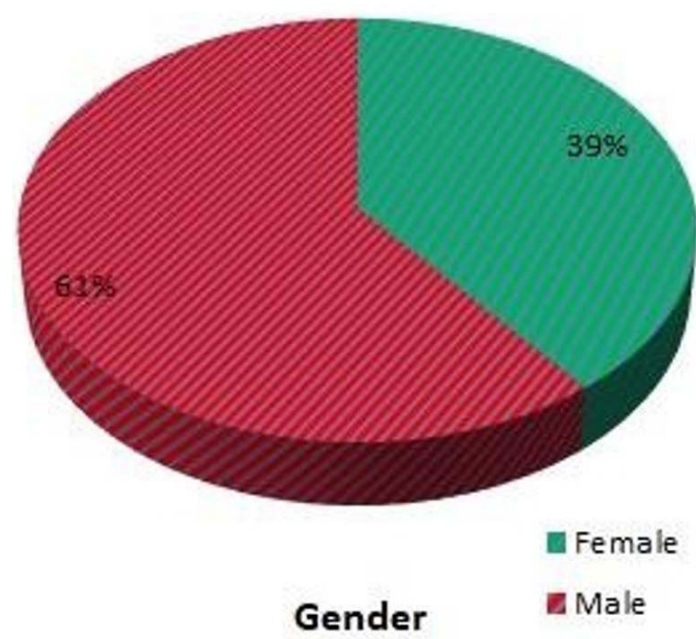

Fig. 1. Gender distribution of COVID-19 patients
CT score. In CT scan, each lobe of the lung is given a CT score ranging from 1 to 5 . In the right lung, there are 3 lobes: upper, middle and lower. Left lung has only two lobes, upper and lower. The CT scan scores are given as follows. When there is $5 \%$ involvement the score is -1, 5- $25 \%$ involvement the score is 2, $25-50 \%$ involvement the score is -- 3, 50-75\% involvement the score is 4,75 $\%$ involvement the score is 5 , showing disease severity.

\section{RESULTS}

In our study, we received samples from 704 patients. The samples were received from patients who got tested positive for COVID-19 either by RT-PCR or CT scan of the lung. We received $8(1.1 \%)$ patients below 10 years of age (between 6 to 10), 175 (24.8\%) patients in 11 - 30 years of age, $276(39.2 \%)$ patients in 31 - 50 years of age, $213(30.2 \%)$ patients in $51-70$ years of age, $32(4.5 \%)$ patients in $71-90$ years of age. The highest number of samples were received in the age group from 31 to 70 years. (Table 1 ). There were $426(60.5 \%)$ male patients and 278 (39.4\%) female patients. (Figure 1) The results of RT PCR showed positive results in 689 (97.8\%) patients and were not detected in 15 patients (2.2\%). (Table 2). The CT scan involvement of the lung took place in the following manner: There was no involvement (not detected) in $423(60 \%)$ patients, $<25 \%$ of involvement in 154 (21.8\%) patients. 25 - 50\% involvement in 92 (13.0\%), $>50 \%$ involvements in $35(8.3 \%)$ patients. (Table 3). This shows that RT-PCR was a more sensitive and reliable parameter in detection of COVID-19. We determined CRP values in various

Table 1. Age wise distribution of patients in COVID 19 patients

\begin{tabular}{lcc}
\hline $\begin{array}{l}\text { Age in } \\
\text { Years }\end{array}$ & $\begin{array}{c}\text { No. of } \\
\text { Patients }\end{array}$ & $\%$ \\
\hline$<10$ & & 1.1 \\
$11-30$ & 175 & 24.8 \\
$31-50$ & 276 & 39.2 \\
$51-70$ & 213 & 30.2 \\
$71-90$ & 32 & 4.5 \\
Total & 704 & 100.0 \\
\hline
\end{tabular}

Mean \pm SD: $43.45+16.29$ 
age groups and the results were expressed in $\mathrm{mg} / \mathrm{l} .8$ patients had CRP in the range of $<5 \mathrm{mg} / \mathrm{l}$ and there were no patients with values $>25 \mathrm{mg} / \mathrm{l}$ in the age group of less than 10 years. In the age group of 11 - 30 years $152(31.39 \%)$ patients had CRP in the range of $<5 \mathrm{mg} / \mathrm{l}$ and $5(5.1 \%)$ patients had in the range of $>25 \mathrm{mg} / \mathrm{l}$. As the age advanced CRP with values $>25 \mathrm{mg} / \mathrm{l}$ was seen in the age group 31 - 50 years 34 (34.7\%), and also in $51-70$ years $51(52.7 \%)$. We had more patients in the age group from 31 - 70 years. (Table 4). CT scan changes involving lungs were also seen more in the same age groups. CT scan involvement of the lung involving $>50 \%$ was seen in the age group between 31 - 50 (38.9\%) years and 51 - 70 (50\%) years. (Table 5). When we compared CT scan with CRP changes, we found CRP values were found to be increased when there is involvement of the lung from $25-50 \%$ (24.5\%) and > 50\% (27.6\%) respectively. (Table 6).

\section{DISCUSSION}

Globally it is a fact that large number of patients have been affected with COVID-19 which is rapidly increasing and asymptomatic

Table 2. Reverse Transcriptase Polymerase Chain Reaction (RTPCR) distribution in COVID 19 patients

\begin{tabular}{lcc}
\hline RT PCR & $\begin{array}{c}\text { No. of Patients } \\
(n=704)\end{array}$ & $\%$ \\
\hline Positive & 689 & 97.8 \\
Negative & 0 & 0.0 \\
ND & 15 & 2.2 \\
\hline
\end{tabular}

patients are also the source of infection. (10) Early determination of key indicators were an important basis to guide treatment strategies to prevent morbidity and mortality. ${ }^{11}$ The most common laboratory findings on admission to hospital include lymphopenia and bilateral ground-glass opacity or patchy changes in chest CT scans. The main pathological changes are damages involving lungs that cripples the patient. It causes damage to the immune complex too. CT dynamic monitoring is done to assess the involvement of the lungs. Most of the time when RT-PCR is negative, the results suggestive of COVID was correlated with the CT scan. ${ }^{12}$ We can see multiple ground glass appearance involving both the lobes of the lungs when there is $>50 \%$ damage. If you find a $50 \%$ increase in lung X-ray findings within 24 to 48 hours, this was considered an early warning indicator of severity of the disease. CT scan can sometimes predict the prognosis of a patient. ${ }^{13}$ According to Zhong Nanshan's latest research, the sensitivity of COVID-19 diagnosis with CT scan alone was $76.4 \%$, and the application of CT scan in COVID-19 was evaluated as useful. ${ }^{14}$ Studies by Chen Lin et al all suggested the correlation of

Table 3. Computerised Tomography scan of lung distribution in patients of COVID

\begin{tabular}{lcc}
\hline CT-SCAN & $\begin{array}{c}\text { No. of Patients } \\
(\mathrm{n}=704)\end{array}$ & $\%$ \\
\hline $25 \%$ & 154 & 21.8 \\
$25-50 \%$ & 92 & 13.0 \\
$50 \%$ & $35 \%$ & 8.3 \\
ND & 423 & 60.0 \\
\hline
\end{tabular}

Table 4. Correlation of Age distribution with C reactive protein in patients of COVID

\begin{tabular}{lcccccc}
\hline \multirow{2}{*}{ Age in Years } & \multicolumn{5}{c}{ CRP } & \multirow{2}{*}{ Total } \\
\cline { 2 - 6 } & ND & $<5 \mathrm{mg} / \mathrm{l}$ & $5-10 \mathrm{mg} / \mathrm{l}$ & $10-25 \mathrm{mg} / 1$ & $>25 \mathrm{mg} / \mathrm{l}$ & \\
\hline 10 & $0(0 \%)$ & $8(1.7 \%)$ & $0(0 \%)$ & $0(0 \%)$ & $0(0 \%)$ & $8(1.1 \%)$ \\
$11-30$ & $0(0 \%)$ & $152(31.9 \%)$ & $14(14.1 \%)$ & $4(13.3 \%)$ & $5(5.1 \%)$ & $175(24.9 \%)$ \\
$31-50$ & $0(0 \%)$ & $192(40.3 \%)$ & $39(39.4 \%)$ & $11(36.7 \%)$ & $34(34.7 \%)$ & $276(39.2 \%)$ \\
$51-70$ & $1(100 \%)$ & $107(22.5 \%)$ & $40(40.4 \%)$ & $14(46.7 \%)$ & $51(52 \%)$ & $213(30.3 \%)$ \\
$71-90$ & $0(0 \%)$ & $17(3.6 \%)$ & $6(6.1 \%)$ & $1(3.3 \%)$ & $8(8.2 \%)$ & $32(4.5 \%)$ \\
Total & $1(100 \%)$ & $476(100 \%)$ & $99(100 \%)$ & $30(100 \%)$ & $98(100 \%)$ & $704(100 \%)$ \\
h4ean + SD & & 39.97 & 48.23 & 48.50 & 53.87 & 43.43 \\
& & +15.88 & +15.04 & +14.23 & +14.05 & +16.29 \\
\hline
\end{tabular}

PM.001**, Significant, Student t Test

Journal of Pure and Applied Microbiology 
Table 5. Computerised Tomography Scan of lung Changes in different age groups

\begin{tabular}{|c|c|c|c|c|c|c|}
\hline \multirow[t]{2}{*}{ Variables } & \multicolumn{4}{|c|}{ CT SCAN } & \multirow[t]{2}{*}{ Total } & \multirow[t]{2}{*}{ P Value } \\
\hline & - & $<25 \%$ & $25-50 \%$ & $>50 \%$ & & \\
\hline \multicolumn{7}{|c|}{ Age in Years } \\
\hline$\leq 10$ & $8(1.9 \%)$ & $0(0 \%)$ & $0(0 \%)$ & $8(1.1 \%)$ & & \\
\hline $11-30$ & $142(33.6 \%)$ & $24(15.6 \%)$ & $8(8.8 \%)$ & $1(2.8 \%)$ & $8(1.1 \%)$ & \\
\hline $31-50$ & $149(35.2 \%)$ & $71(46.1 \%)$ & $42(46.2 \%)$ & $14(38.9 \%)$ & $276(39.2 \%)$ & \\
\hline $51-70$ & $105(24.8 \%)$ & $53(34.4 \%)$ & $37(40.7 \%)$ & $18(50 \%)$ & $213(30.3 \%)$ & $<0.001 * *$ \\
\hline $71-90$ & $19(4.5 \%)$ & $6(3.9 \%)$ & $4(4.4 \%)$ & $3(8.3 \%)$ & $32(4.5 \%)$ & \\
\hline
\end{tabular}

Table 6. Comparison of C- Reactive protein and Computerised Tomography of lung changes in COVID-19

\begin{tabular}{|c|c|c|c|c|c|c|c|}
\hline \multirow[t]{2}{*}{ Variables } & \multicolumn{5}{|c|}{ CRP } & \multirow[t]{2}{*}{ Total } & \multirow[t]{2}{*}{ P Value } \\
\hline & ND & $<5 \mathrm{mg} / \mathrm{l}$ & $5-10 \mathrm{mg} / \mathrm{l}$ & $10-25 \mathrm{mg} / \mathrm{l}$ & $>25 \mathrm{mg} / \mathrm{l}$ & & \\
\hline \multicolumn{8}{|l|}{ CT SCAN } \\
\hline ND & $0(0 \%)$ & $352(73.9 \%)$ & $22(22.2 \%)$ & $11(36.7 \%)$ & $38(38.8 \%)$ & $423(60.1 \%)$ & $<0.001^{* *}$ \\
\hline$<25 \%$ & $0(0 \%)$ & $104(21.8 \%)$ & $38(.4 \%)$ & $3(10 \%)$ & $9(9.2 \%)$ & $154(21.9 \%)$ & $<0.001 * *$ \\
\hline $25-50 \%$ & $0(0 \%)$ & $18(3.8 \%)$ & $38(38.4 \%)$ & $11(36.7 \%)$ & $24(24.5 \%)$ & $91(12.9 \%)$ & $<0.001 * *$ \\
\hline$>50 \%$ & $1(100 \%)$ & $2(0.4 \%)$ & $1(1 \%)$ & $5(16.7 \%)$ & $27(27.6 \%)$ & $36(5.1 \%)$ & $<0.001^{* *}$ \\
\hline
\end{tabular}

the CT scan in the diagnosis and evaluation of COVID-19. ${ }^{4} \mathrm{CRP}$ is a type of protein and is found to be raised in response to inflammation. Generally, CRP level is found to be on an increased level in bacterial infections than in viral infections. To our surprise, many COVID-19 patients in this study showed raised CRP levels mostly in the age group between 31 - 70 years, in addition to CT changes involving $>50 \%$ involvement of the lungs in the same age groups. It is consistent with Wang et al study. ${ }^{15}$ It is an important index for the diagnosis and assessment of severe pulmonary infectious diseases. ${ }^{16}$ Moreover, critical cases in this study showed significantly raised levels of CRP than non-critical patients, which suggested that CRP may be a serum marker of disease severity in COVID-19 patients. The logistic regression analysis demonstrated that CRP was indeed related to disease progression. Patients presenting with pneumonia were found to have raised CRP level. ${ }^{17}$ In Matsumoto's study we found raised levels of CRP levels in severe pneumonia. His study showed that CRP levels and the area of increased lung lesion increased as the disease progressed. ${ }^{18}$ which was correlating with our study.

\section{CONCLUSIONS}

Early intervention is required to prevent mortality among severe COVID-19 patients. Raise in CRP level values could be used as a valuable marker initially to start the treatment early. As the disease progresses, CRP can be used as a prognostic marker to assess the severity which is correlating with our study. This was observed from the CT score involvement of the lung. However, a large sample size is required to confirm these results. We need to focus to assess the patient initially based on clinical findings and carry out relevant investigations to prevent morbidity and mortality.

\section{ACKNOWLEDGMENTS}

I would like to acknowledge my guides, Dr. V. Kalpana Devi and Dr. E. Subbalakshmi for providing inputs of their knowledge in the study. Besides, I would like to thank Dr. Karthick Kalaichelvan, Dr.Rajasekaran and Dr.R.Malathi who were supportive in this project. I would like to thank the statistician Dr. K. P. Suresh for the data analysis and Miss Shivani Ramakrishnan for correcting the grammatical errors.

\section{CONFLICT OF INTEREST}

The authors declare that there is no conflict of interest. 


\section{AUTHORS' CONTRIBUTION}

All authors listed have made a substantial, direct and intellectual contribution to the work, and approved it for publication.

\section{FUNDING}

None.

\section{DATA AVAILABILITY}

The datasets generated during and/or analysed during the current study are available from the corresponding author on reasonable request.

\section{ETHICS STATEMENT}

The study was approved by the Institutional Ethics Committee, A.C.S. Medical College Hospital, Chennai, India (No.98/2020/1EC/ ACSMCH Dt. 16.12.2020).

\section{REFERENCES}

1. Lu Hongzhou, CW Statton, YW Tang. Outbreak of pneumonia of unknown etiology in Wuhan, China: The mystery and the miracle. J Med Virol. 2020;92(4):401402. doi: $10.1002 / j m v .25678$

2. Hui DS, Azhar El, Madani TA, et al. The continuing 2019nCoV epidemic threat of novel coronaviruses to global health - the latest 2019 novel coronavirus outbreak in Wuhan, China. Int J Infect Dis. 2020;91:264-266. doi: 10.1016/j.ijid.2020.01.009

3. Yoon SH, Lee KH, Kim JY, et al. Chest radiographic and CT findings of the 2019 novel coronavirus disease (COVID-19): analysis of nine patients treated in Korea. Korean J Radiol. 2020;21(4):494-500. doi: 10.3348/ kjr.2020.0132

4. Lin C, Ding Y, Xie B, et al. Asymptomatic novel coronavirus pneumonia patient outside Wuhan: the value of $\mathrm{CT}$ images in the course of the disease. Clin Imaging. 2020;63:7-9. doi: 10.1016/j.clinimag.2020.02.008

5. Petrilli CM, Jones SA, Yang J, et al. Factors associated with hospital admission and critical illness among 5279 people with coronavirus disease 2019 in New York City: prospective cohort study. BMJ. 2020;369:m1966. doi: 10.1136/bmj.m1966
6.

Rosner B. Fundamentals of Biostatistics, $5^{\text {th }}$ Ed, Duxbury; 2000:80-240.

7. Riffenburg RH, Statistics in Medicine, $2^{\text {nd }}$ Ed, Academic press; 2005:85-125.

8. Rao PSSS, Richard J. An Introduction to Biostatistics, A manual for students in health sciences, New Delhi: Prentice hall of India. 2006;4th Ed: 86-160.

9. Suresh KP, Chandrasekhar S. Sample Size estimation and Power analysis for Clinical research studies. J Hum Reprod Sci. 2012;5(1):7-13. doi: 10.4103/09741208.97779

10. Machase E. China coronavirus: mild but infectious cases may make it hard to control outbreak, Report warms. BMJ. 2020:368:m325. doi: 10.1136/bmj.m325

11. Li G, De Clercq E. Therapeutic options for the 2019 novel coronavirus (2019-nCoV). Nat Rev Drug Discov. 2020;19(3):149-150. doi: 10.1038/d41573-020-000160

12. Sekar P, Menezes GA, Shivappa P, George BT, Hossain A. Considerations in Real-time Reverse Transcription Polymerase Chain Reaction (RT-PCR) for the Detection of SARS-CoV-2 from Nasopharyngeal Swabs. J of Pharm Res Int. 2021;33(17):68-78. doi: 10.9734/jpri/2021/ v33i1731309

13. Lee KS. Pneumonia associated with 2019 novel coronavirus: can computed tomographic findings help predict the prognosis of the disease? Korean J Radiol. 2020;21(3):257-258. doi: 10.3348/kjr.2020.0096

14. Wang L. C-reactive protein in the early stages of COVID-19. Med Mal Infect. 2020;50(4):332-334.

15. Wang G, Wu C, Zhang Q, et al. C-Reactive Protein Level May Predict the Risk of COVID-19 Aggravation. Open Forum Infect Dis. 2020;7(5):ofaa153. doi: 10.1093/ ofid/ofaa153

16. Chalmers S, Khawaja A, Wieruszewski PM, et al. Diagnosis and treatment of acute pulmonary inflammation in critically ill patients: the role of inflammatory biomarkers. World I Crit Care Med. 2019;8(5):59-71. doi: 10.5492/wjccm.v8.i5.74

17. Warusevitane A, Karunatilake D, Sim J, Smith C, Roffe C. Early diagnosis of pneumonia in severe stroke: clinical features and the diagnostic role of C-reactive protein. PloS One. 2016;11(3):e0150269. doi: 10.1371/journal. pone. 0150269

18. Matsumoto H, Kasai T, Sato A, et al. Association between C-reactive protein levels at hospital admission and long-term mortality in patients with acute decompensated heart failure. Heart Vessels. 2019;34(12):1961-1968. doi: 10.1007/s00380-01901435-9 